\title{
Pancreatic Fistula After Pancreaticoduodenectomy Is Iatrogenic in Nature
}

\author{
Hari S. Shukla ${ }^{1}$
}

Received: 24 October 2015 / Accepted: 30 October 2015 /Published online: 16 November 2015

(C) Association of Surgeons of India 2015

Keywords Pancreaticoduodenectomy · Pancreatic fistula · Delayed gastric emptying · Complications · Iatrogenic

Pancreatic fistula after pancreaticoduodenectomy (PD) is a dreaded complication not easily accepted by the operative surgeons to be iatrogenic in nature. How then measures to prevent postoperative pancreatic fistula (POPF) are in equal measure effective or ineffective be it use of octreotide, pancreaticogastrostomy (PG), or different avatars of pancreaticojejunostomy $(\mathrm{PJ})$, and use of pancreatic duct stents [1]. Vilification of texture of the pancreas in to soft or firm/hard in nature as the cause of POPF is the lament of many pancreatic surgeons.

Postoperative morbidity of PD is mainly due to POPF, and it overshadows other important morbidities and general complications that may occur in up to $17.5 \%$ of the patients [2]. POPF is also thought to be the culprit behind most post pancreatectomy hemorrhages and delayed gastric emptying.

The PJ versus PG debate continues to be inconclusive of the superiority of one over the other confirming that

Hari S. Shukla

harishukla@gmail.com

1 Department of Surgical Oncology, Institute of Medical Sciences, Banaras Hindu University, Varanasi 221005, Uttar Pradesh, India anastomotic skill of the surgeon is the most important factor [3]; a failure here makes the procedure failure qualify for an iatrogenic tag, thus performing pancreatic anastomosis becomes a challenge. To this endeavor of pancreatic anastomosis, neither octreotide nor pancreatic duct stents or drainage is effective. Therefore, the cause of POPF zeros down to the anastomotic skills; a failure of which is iatrogenic.

The size of the pancreatic duct, small caliber or over $3 \mathrm{~mm}$ is important for the ease of operation, i.e., the pancreatic anastomosis. The texture of the pancreas soft or firm/hard is also an important factor in the procedure of pancreatic-gut anastomosis as it dictates sutureholding quality of the pancreas indirectly passing of the surgical skill deficiency to duct size or the texture of the pancreas.

$\mathrm{PD}$ is a time-consuming operation with the surgeon involved in resection of the pancreatic head-already an attention-, emotion-, and skill-consuming procedure - with an important skillful task still pending (after resection) of restoration of the pancreatic-gut continuity. It is at this end of PD operative procedure that a dedicated multicenter study is required to examine if surgical fatigue is in anyway influencing the occurrence of POPF. If so, it will be iatrogenic in true sense of the term. There is already an indication of this as with the increasing experience of the pancreatic surgeon the incidence of POPF declines and hence the emphasis on high-volume hospitals and high-volume surgeons for carrying out these complex procedures [4].

\section{Compliance with Ethical Standards}

Conflict of Interest None. 


\section{References}

1. Lai EC, Lau SH, Lau WY (2009) Measures to prevent pancreatic fistula after pancreatoduodenectomy: a comprehensive review. Arch Surg 144(11):1074-80

2. Rosso E, Bachellier P, Oussoultzoglou E, Scurtu R, Meyer N, Nakano H, Verasay G, Jaeck D (2006) Toward zero pancreatic fistula after pancreaticoduodenectomy with pancreaticogastrostomy. Am J Surg 191(6):726-32, discussion 733-4

3. Kleespies A, Albertsmeier M, Obeidat F, Seeliger H, Jauch KW, Bruns CJ (2008) The challenge of pancreatic anastomosis. Langenbecks Arch Surg 393(4):459-71

4. Birkmeyer JD, Siewers JE, Finlayson EVA, Stukel TA, Lucas FE, Batista I et al (2002) Hospital volume and hospital mortality in the United States. N Engl J Med 346:1128-37 